\title{
Quality of life in patients with HTLV-I associated myelopathy/tropical spastic paraparesis
}

\author{
Qualidade de vida em pacientes com mielopatia associada ao HTLV-I/paraparesia \\ espástica tropical
}

José Vicente Pereira Martins', Abrahão Fontes Baptista², Abelardo de Queiroz Campos Araújo1,3

\begin{abstract}
Objective: To assess the quality of life (QoL) of patients with HTLV-I-associate myelopathy/tropical spastic paraparesis (HAM/TSP) and to correlate it with specific aspects of the disease. Methods: Fifty-seven HAM/TSP patients completed the SF-36 QoL questionnaire. They were also asked about common complaints related to the disease, and we looked for associations between QoL and these complaints. Results: Patients with HAM/TSP showed a strong negative association to QoL. Pain was the condition which most affected their QoL. The practice of physical activity is associated with better QoL in five out of eight domains of the scale. Conclusion: HAM/TSP leads to a poor QoL, mostly influenced by pain. Physical activity may have a positive association to QoL of these patients.
\end{abstract}

Key words: HTLV-I-associate myelopathy/tropical spastic paraparesis, quality of life, SF-36, motor activity.

\section{RESUMO}

Objetivo: Avaliar a qualidade de vida (QV) em pacientes com mielopatia associada ao HTLV-I/paraparesia espástica tropical (MAH/PET) e correlacioná-la com aspectos específicos da doença. Métodos: Cinquenta e sete pacientes com MAH/PET completaram o questionário de qualidade de vida SF-36. Também foram feitas perguntas sobre queixas comuns relacionadas à doença e investigadas posteriormente associações entre QV e essas queixas. Resultados: Pacientes com MAH/PET apresentaram uma associação negativa com a QV. A dor foi a condição que mais afetou a QV. A prática de atividade física foi associada a uma melhor QV em cinco dos oito domínios da escala. Conclusão: MAH/PET leva a uma pior $\mathrm{QV}$, principalmente influenciada pela dor. A atividade física pode estar positivamente associada à QV destes pacientes.

Palavras-Chave: mielopatia associada ao HTLV-I/paraparesia espástica tropical, qualidade de vida, SF-36, atividade motora.

The human t-cell lymphotropic virus type 1 (HTLV - I), a human deltaretrovirus, is the etiological agent of adult T-cell leukemia and various inflammatory diseases, including HTLV-I associated myelopathy (HAM)/tropical spastic paraparesis (TSP) ${ }^{1}$. HTLV-I infection was first described in the 1980s, being endemic in Southern Japan, the Caribbean, Central and South Africa, and South America ${ }^{2}$.

In 1989, the World Health Organization created the term HTLV-I associated myelopathy/tropical spastic paraparesis (HAM/TSP) for the neurological syndrome associated with this virus ${ }^{3}$. HAM/TSP is mainly a spinal cord syndrome characterized by a chronic progressive spastic paraparesis, mild sensory signs and neurogenic bladder, but in some patients it can show a rapid deterioration ${ }^{4}$.

The neurological examination usually shows weakness and spasticity in the lower limbs, increased deep tendon reflexes, bilateral Babinski sign, clonus and gait abnormalities $^{5}$ Other complaints include low back pain, numbness and dysesthesias in the legs and foot.

As HAM/TSP causes limitations on daily living activities, so it is important to evaluate the association of these conditions with the quality of life of the patients ${ }^{6}$. In a population with chronic diseases, measurement of the quality of life (QoL) provides a meaningful way to understand the consequences of the illness when cure is not possible.

Quality of life, as defined by World Health Organization, takes into account the perception of the individuals about their own position in life and involves cultural context, goals, expectations, parameters and social relations ${ }^{7}$.

Researchers have examined a myriad of phenomena that influence QOL in older adults. For example, spirituality, social networks, supportive communities and a variety of health-

${ }^{1}$ Federal University of Rio de Janeiro (UFRJ), Rio de Janeiro RJ, Brazil;

${ }^{2}$ Biomorphology Department, Federal University of Bahia (UFBA), Salvador BA, Brazil;

${ }^{3}$ Reference Center on Neuroinfections and HTLV, Evandro Chagas Clinical Research Institute (IPEC), FIOCRUZ, Rio de Janeiro, Brazil.

Correspondence: José Vicente Pereira Martins; Rua Jornalista Henrique Cordeiro 120 / 1405; 22631-450 Rio de Janeiro RJ - Brasil; E-mail:

josevicentemartins@terra.com.br

Conflict of interest: There is no conflict of interest to declare.

Received 18 September 2011; Received in final form 16 November 2011; Accepted 23 November 2011 
promoting activities were associated with improved QOL. At the same time, loneliness, depression, fear and isolation were associated with decreased QOL in older adults ${ }^{8}$.

Over the past 20 years, hundreds of instruments have been developed to measure patient's quality of life. The SF-36 Health Survey was created to be a generic questionnaire for the evaluation of the quality of life with an easy and comprehensive administration. It is a measure of health status as opposed to one that targets a specific age, disease or treatment group. Accordingly, the SF-36 has been proven to be useful in comparing general and specific population, estimating the relative burden of different disease, differentiating the health benefits produced by a wide range of different treatments and screening individuals' patients, and is used for people with chronic illness, such as spinal cord injury, multiple sclerosis and stroke ${ }^{9}$.

Sustaining an injury to the spinal cord may result in neurogenic bowel and bladder function, varying degrees of motor paralysis, sensory dysfunction and spasticity. For this reason, many studies have measured the consequence of the traumatic spinal cord injury negatively on a QOL, using the SF-36 ${ }^{10}$. The SF-36 could be a very useful tool for assessing the quality of life of the patients with HAM/TSP and can help healthcare professionals to focus their therapeutic strategies in areas that may jeopardize the welfare of these patients.

Therefore, the primary aim of this study was to evaluate patients suffering from HAM/TSP by applying the SF-36 questionnaire and to compare it with some more relevant findings related to the condition itself. These findings are complaints which are usually mentioned by patients with HAM/TSP during regular assessments, such as: problems with locomotion, lack of the bladder control, pain, some important aspects concerning time of the duration of symptoms and if they are treated with physiotherapy and exercises. These questions were asked and compared with SF-36 questionnaire.

\section{METHODS}

This was an observational, cross-sectional, study conducted at the Reference Center for Neurological Infections (Evandro Chagas Hospital, IPEC-FIOCRUZ) in Rio de Janeiro, Brazil, from March to December of 2007. The initial sample was composed of 107 patients who fulfilled the World Health Organization $^{11}$ (WHO) criteria for HAM/TSP and were in regular follow up at the HTLV outpatient clinic of the IPECFIOCRUZ. The exclusion criteriawere:patients withHAM/TSP who showed some comorbidities not related to HTLV-I infection (diabetes, chronic limiting osteoarticular diseases, kidney and liver failure, neoplasm, blindness, chronic obstructive pulmonary disease, decompensate hypo or hyperthyroidism, congestive heart failure, chronic hepatitis in activity and acquired immunodeficiency syndrome); patients with HAM/TSP with some cognitive, behavioral or psychiatric dysfunction that would not allow proper completion of the questionnaire; patients who had changes in their pharmacological or physical therapy treatment in the four weeks before the date of completion of the questionnaire and illiterate patients. Based on these criteria, 50 patients had to be excluded.

Only one patient was excluded due to illiteracy. The others were excluded due to their medical comorbidities or due to the presence of other diseases.

Quality of life was assessed by the validated Brazilian version of the SF-36 questionnaire ${ }^{9}$. The SF-36 is a generic health status measure. It contains 8 domains: physical function, role physical, mental health, role emotional, vitality, pain, social functioning and general health. The 8 domains can be aggregated to form 2 summary scales, a physical component score (PCS) and a mental component score (MCS). The score for each scale ranges from 0 to 100. A high score indicates favorable quality of life measures. An additional question in the SF-36 relates to changes in health over time.

The SF-36 was translated into Portuguese in 1997 and has shown validity and internal consistency when used in general populations ${ }^{9}$. The subjects answered the questionnaire in a room in the HTLV-I outpatient department at IPEC FIOCRUZ, Rio de Janeiro. In case of any doubt, the examiner could only repeat the question once, without any further explanation. The SF-36 was read aloud by the same researcher, with the same voice intonation in order not to have any kind of influence on the answers.

After answering the SF-36, patients were also questioned about some important aspects concerning their health. The questions were:

1. What does bother you the most at the moment? Options: a) pain, b) locomotion, c) no bladder control, d) to depend on others.

2. How long have you been feeling the symptoms related to the HAM/TSP for? Options: a) 10 years, b) more than 10 years.

3. Can you walk or do you need a wheelchair? Options: a) walk, b) wheelchair.

4. Do you have bladder control? Options: a) yes, b) no.

5. Do you feel low back pain or/and pain in the lower limbs? Options: a) yes, b) no.

6. Have you been doing physiotherapy or exercising regularly assisted by a professional? Options: a) yes, b) no.

The assessment of the association of HTLV-I to the quality of life related to health of these patients was done by comparing the scores of the SF-36 domains with the answers to the questions 2 till 6 mentioned above.

The study was submitted and approved by the Ethical Committee of IPEC-FIOCRUZ, and all subjects signed and gave consent. 
The Mann-Whitney test, the variance analysis of Kruskal-Wallis (ANOVA non-parametric) and the Spearman correlation coefficient were used in the statistical analysis with an alpha value of $5 \%(p<0.05)$ for significance. The descriptive data was presented as medians, minimum and maximum values.

Table 1. Sociodemographic and general health status data.

\begin{tabular}{lccc}
\multicolumn{1}{c}{ Variable } & Category & $\mathrm{n}$ & $\%$ \\
\hline Time of symptoms & 1 a 5 & 10 & 17.5 \\
& 5 a 10 & 14 & 24.6 \\
Greater discomfort & 10 years & 33 & 57.9 \\
& Pain & 9 & 15.8 \\
& Locomotion & 36 & 63.2 \\
& Urine & 5 & 8.8 \\
Locomotion & Depend on others & 7 & 12.3 \\
& Wheelchair & 15 & 26.3 \\
Well-being with physical activities & Walk & 42 & 73.7 \\
Gender & Yes & 38 & 66.7 \\
& Yes & 47 & 82.5 \\
& Female & 37 & 64.9 \\
\hline
\end{tabular}

\section{RESULTS}

Out of 57 patients, 37 were female (64.9\%) and the mean age was 52.4 years. The majority of participants had symptoms for more than 10 years (57.9\%). Regarding locomotion, $73.7 \%$ of the patients were able to walk, while $26.3 \%$ were wheelchair bound. Most patients $(63.2 \%)$ reported that their greater discomfort was related to their gait impairment, followed by pain (Table 1).

Patients with pain had lower SF-36 scores in the domains: general health, pain, vitality and mental health, when compared with the subgroup of patients without pain (Table 2). Patients who practiced regular physical exercises had better scores in other domains (Table 3). Regarding locomotion, patients restricted to a wheelchair presented lower scores of functional capacity than the subgroup who were still able to walk. The subgroup of patients who had bladder control showed scores of functional capacity significantly higher than the group without it. There was no statistically significant difference in terms of age, gender and the SF-36 questionnaire.

Table 2. Correlation between low back pain and SF-36.

\begin{tabular}{|c|c|c|c|c|c|c|}
\hline SF-36 (\%) & Pain & $n$ & Median & Min. & Max. & $p$-value* \\
\hline \multirow[t]{2}{*}{ General health } & yes & 38 & 38.5 & 0 & 97 & \multirow{2}{*}{0.009} \\
\hline & no & 19 & 67.0 & 5 & 92 & \\
\hline \multirow[t]{2}{*}{ Physical function } & yes & 38 & 10.0 & 0 & 80 & \multirow{2}{*}{0.42} \\
\hline & no & 19 & 15.0 & 0 & 55 & \\
\hline \multirow[t]{2}{*}{ Physical role } & yes & 38 & 37.5 & 0 & 100 & \multirow{2}{*}{0.43} \\
\hline & no & 19 & 75.0 & 0 & 100 & \\
\hline \multirow{2}{*}{ Emotional role } & yes & 38 & 16.7 & 0 & 100 & \multirow{2}{*}{0.14} \\
\hline & no & 19 & 100.0 & 0 & 100 & \\
\hline \multirow[t]{2}{*}{ Social function } & yes & 38 & 50.0 & 0 & 100 & \multirow{2}{*}{0.10} \\
\hline & no & 19 & 62.5 & 0 & 100 & \\
\hline \multirow[t]{2}{*}{ Bodily pain } & yes & 38 & 46.5 & 0 & 100 & \multirow{2}{*}{0.0001} \\
\hline & no & 19 & 100.0 & 31 & 100 & \\
\hline \multirow[t]{2}{*}{ Vitality } & yes & 38 & 35.0 & 0 & 100 & \multirow{2}{*}{0.017} \\
\hline & no & 19 & 55.0 & 20 & 95 & \\
\hline \multirow[t]{2}{*}{ Mental health } & yes & 38 & 52.0 & 0 & 100 & \multirow{2}{*}{0.024} \\
\hline & no & 19 & 76.0 & 0 & 100 & \\
\hline
\end{tabular}

*Mann-Whitney, $p<0.05$.

Table 3. Physical exercise and SF-36.

\begin{tabular}{|c|c|c|c|c|c|c|}
\hline SF-36 (\%) & Exercise & $n$ & Median & Min. & Max. & $p$-value* \\
\hline \multirow[t]{2}{*}{ General health } & yes & 28 & 67.0 & 15 & 97 & \multirow{2}{*}{0.0003} \\
\hline & no & 29 & 30.0 & 0 & 87 & \\
\hline \multirow[t]{2}{*}{ Physical function } & yes & 28 & 15.0 & 0 & 80 & \multirow{2}{*}{0.10} \\
\hline & no & 29 & 5.0 & 0 & 70 & \\
\hline \multirow[t]{2}{*}{ Physical role } & yes & 28 & 50.0 & 0 & 100 & \multirow{2}{*}{0.42} \\
\hline & no & 29 & 25.0 & 0 & 100 & \\
\hline \multirow[t]{2}{*}{ Emotional role } & yes & 28 & 100.0 & 0 & 100 & \multirow[b]{2}{*}{0.22} \\
\hline & no & 29 & 0.0 & 0 & 100 & \\
\hline \multirow[t]{2}{*}{ Social function } & yes & 28 & 62.5 & 0 & 100 & \multirow{2}{*}{0.024} \\
\hline & no & 29 & 50.0 & 0 & 100 & \\
\hline \multirow[t]{2}{*}{ Bodily pain } & yes & 28 & 61.5 & 0 & 100 & \multirow{2}{*}{0.024} \\
\hline & no & 29 & 51.0 & 0 & 100 & \\
\hline \multirow[t]{2}{*}{ Vitality } & yes & 28 & 57.5 & 20 & 100 & \multirow{2}{*}{0.0001} \\
\hline & no & 29 & 25.0 & 0 & 75 & \\
\hline \multirow[t]{2}{*}{ Mental health } & Yes & 28 & 80.0 & 20 & 100 & \multirow{2}{*}{0.0002} \\
\hline & No & 29 & 48.0 & 0 & 96 & \\
\hline
\end{tabular}

*Mann-Whitney, $p<0.05$. 
Table 4. Duration of the symptoms and SF-36.

\begin{tabular}{|c|c|c|c|c|c|c|}
\hline SF-36 (\%) & Symptoms & $\mathrm{n}$ & Median & Min. & Max. & $p$-value* \\
\hline \multirow[t]{2}{*}{ General health } & $\leq 10$ years & 24 & 57.0 & 10 & 92 & \multirow{2}{*}{0.052} \\
\hline & $>10$ years & 33 & 40.0 & 0 & 97 & \\
\hline \multirow[t]{2}{*}{ Physical function } & $\leq 10$ years & 24 & 10.0 & 0 & 80 & \multirow{2}{*}{0.88} \\
\hline & $>10$ years & 33 & 15.0 & 0 & 70 & \\
\hline \multirow{2}{*}{ Physical role } & $\leq 10$ years & 24 & 0.0 & 0 & 100 & \multirow{2}{*}{0.34} \\
\hline & $>10$ years & 33 & 50.0 & 0 & 100 & \\
\hline \multirow[t]{2}{*}{ Emotional role } & $\leq 10$ years & 24 & 33.3 & 0 & 100 & \multirow{2}{*}{0.33} \\
\hline & $>10$ years & 33 & 100.0 & 0 & 100 & \\
\hline \multirow[t]{2}{*}{ Social function } & $\leq 10$ years & 24 & 50.0 & 0 & 100 & \multirow{2}{*}{0.79} \\
\hline & $>10$ years & 33 & 50.0 & 0 & 100 & \\
\hline \multirow[t]{2}{*}{ Bodily pain } & $\leq 10$ years & 24 & 51.5 & 0 & 100 & \multirow{2}{*}{0.90} \\
\hline & $>10$ years & 33 & 51.0 & 0 & 100 & \\
\hline \multirow[t]{2}{*}{ Vitality } & $\leq 10$ years & 24 & 52.5 & 0 & 100 & \multirow{2}{*}{0.56} \\
\hline & $>10$ years & 33 & 40.0 & 0 & 95 & \\
\hline \multirow[t]{2}{*}{ Mental health } & $\leq 10$ years & 24 & 58.0 & 0 & 100 & \multirow{2}{*}{0.65} \\
\hline & $>10$ years & 33 & 56.0 & 0 & 96 & \\
\hline
\end{tabular}

*Mann-Whitney, $p<0.05$.

Patients with more than 10 years of symptoms showed lower general health domain score than the subgroup with duration of symptoms $\leq 10$ years. The relationship between duration of symptoms and SF-36 can be seen in Table 4 .

\section{DISCUSSION}

The aim of this study was to evaluate the association of $\mathrm{HAM} / \mathrm{TSP}$ to the quality of life of the patients with it. The sample had low scores in two components: physical and mental, showing that patients with HAM/TSP reported changes in their quality of life in both physical and emotional aspects.

Most patients were female, had a mean age of 52.4 years and manifested symptoms of the disease for more than ten years, which is consistent with epidemiological data already described in the literature ${ }^{5}$.

The most common complaint was change in gait patterns, followed by pain. Franzoi and colleagues ${ }^{12}$ identified that gait disorders was the most common complaint in a sample of 60 patients with HAM/TSP, followed by complaints related to a lack of bladder control, which in our sample was the third biggest complaint. Most patients reported low back pain, which is consistent with previous studies that demonstrated the relevance of this symptom in patients with $\mathrm{HAM} / \mathrm{TSP}^{13}$.

As locomotion disorders were common complaints, strategies to improve patients' gait or prescription of walking aid should be the aims in rehabilitation programs for these individuals. Future studies should be done in order to investigate the usefulness of preventive physical therapy or regular exercises aiming to postpone the use of a wheelchair.

Patients who reported low back pain and/or pain in the lower limbs had lower scores in the domains of general health, pain, vitality and mental health. The questionnaire revealed that pain affects both the physical and mental aspects of the quality of life. This symptom is often found in the initial stages of the disease and is associated with worsening of functionality ${ }^{14}$ and quality of life.

Boureau and colleagues ${ }^{15}$ found that the pain in these patients had neuropathic and nocioceptive characteristics, which demonstrates that the persistence and intensity of this symptom can interfere in their daily routine. The vitality domain contains items that assess the level of fatigue and energy. The lowest score of vitality in patients who reported pain is consistent with the work of Miller and colleagues ${ }^{16}$, who demonstrated that fatigue is a common symptom in neurological patients and that pain increases the feeling of fatigue. Therefore, there is a need to study better ways to control and relieve patient's pain by administering pharmacological and non-pharmacological therapy.

Patients who reported practicing regular physical exercises had higher scores in the domains of general health, pain, vitality, mental health and also in social functioning. This suggests that the regular practice of any physical activity can be effective in the perception of quality of life of these patients. Literature has shown the benefits of exercise to improve the quality of life in individuals with chronic neurological conditions and other diseases ${ }^{17}$. Because patients with HAM/TSP frequently show secondary muscle impairment and postural problems due to inadequate biomechanical gait patterns, exercise can minimize these musculoskeletal abnormalities, leading to a better overall well-being. In addition, patients confined to a wheelchair could prevent many side-effects of such inactivity.

Urinary symptoms are found in the early stages of the disease $^{18}$ and are considered important factors that worsen the quality of life of patients with HAM/TSP. Patients with better bladder control had higher scores in the domain of functional capacity. This item assesses the presence and extent of limitations related to physical capacity. This is in accordance with a previous paper ${ }^{6}$ which assessed the functional profile of patients with HAM/TSP using the FIM - Functional Independence Measure. This study demonstrated that 
the most affected functional area was the handling of the bladder.

It was observed that patients with longer duration of symptoms had a lower score in the general health domain. This domain assesses how a person feels about their overall health. Since HAM/TSP is a chronic progressive disease, patients could feel less healthy when self-evaluating their own health over the years.

The duration of symptoms and the quality of life is the subject of great controversy in literature. Some authors found an inverse correlation ${ }^{19,20}$, confirming a higher score on the quality of life in chronic spinal cord patients, believing that this was due to resignation or acceptance of their condition.

It was observed in the SF-36 questionnaire that patients who performed physical activities presented higher scores in five out of eight domains. Nevertheless, type, frequency or intensity of physical activities that improved these patients' well-being were not asked. Future studies should be done to investigate these aspects and check which are the best advices and exercise prescriptions for patients with HAM/TSP and what are the best therapeutic tools for reducing the pain of these subjects.

As a note of caution, the SF-36, as a generic questionnaire, is an instrument that does not assess specific issues related to patients with HAM/TSP and has its limitations on the questions asked to patients who are confined to a wheelchair. However, it is widely used, validated and useful for comparisons with other chronic and disabling diseases.

In conclusion, we found that patients with HAM/TSP showed low scores in all domains in the quality of life questionnaire SF-36. There was no statistically significant difference in terms of age, gender and SF-36. Patients with bladder control had higher scores in the domain of functional capacity and patients with longer duration of symptoms had a lower score in the general health domain.

Patients who reported practicing regular physical exercises had higher scores in the domains of general health, pain, vitality, mental health and also in social functioning, showing that physical exercises can be related to a better quality of life of these individuals.

Otherwise, patients who reported pain had lower scores in the domains of general health, pain, vitality and mental health, demonstrating that this symptom had a strong negative association with their quality of life. Thus, the recommendation of a physical therapy program or physical activity should be stimulated, as well as specific strategies to relieve pain.

\section{References}

1. Gessain A, Barin F, Vernant JC, et al. Antibodies to human T-lymphotropic virus type-I in patients with tropical spastic paraparesis. Lancet 1985;2:407-410.

2. Vrielink H, Zaaijer HL, Reesink HW. The clinical relevance of HTLV type I and II in transfusion medicine. Transfus Med Rev 1997;11:173-179.

3. World Health Organization. Report of the scientific group on HTLV-I infection and associated diseases. WHO Wkly Epidemiol Rec 1989;49:382-383.

4. Osame M, Usuku K, Izumo S, et al. HTLV-I associated myelopathy, a new clinical entity. Lancet 1986;1:1031-1032.

5. Milagres AC, Jorge ML, Marchiori PE, Segurado AA. Human T cell lymphotropic virus tipe 1-associated myelopathy in São Paulo, Brazil. Epidemiologic and clinical features of an university hospital cohort. Neuroepidemiology 2002;21:153-158.

6. Franzoi AC, Araujo AQ. Disability profile of patients with HTLV-I associated myelopathy/tropical spastic paraparesis using The Functional Independence Measure (FIM). Spinal Cord 2005;43:236240.

7. The WHOQOL Group. The World Health Organization quality of life assessment (WHOQOL): position paper from the World Health Organization. Soc Sci Med 1995;41:1403-1409.

8. Register ME, Herman J. Quality of life revisited: the concept of connectedness in older adults. ANS Adv Nurs Sci 2010;33:53-63.

9. Ciconelli RM, Ferraz MB, Santos W, Meinão I, Quaresma MR. Tradução para a língua portuguesa e validação do questionário genérico de avaliação de qualidade de vida SF-36 (Brasil SF-36). Rev Bras Reumatol 1999;39:143-150.

10. Hill MR, Noonan VK, Sakakibara BM, Miller WC (SCIRE Research Team). Quality of life instruments and definitions in individuals with spinal cord injury: a systematic review. Spinal Cord 2010;48:438-450.
11. Osame M. Review of WHO Kagoshima meeting and diagnostic guidelines for HAM/TSP. In: Blattner W (Ed). Human Retrovirology: HTLV. 1st ed. Raven Press: New York 1990:191-197.

12. Franzoi AC, Araújo AQC. Disability and determinants of gait performance in tropical spastic paraparesis/HTLV-I associated myelopath (HAM/TSP). Spinal Cord 2007;45:64-68.

13. Ferreira AS, Costa VV, Saraiva RA. The incidence of neuropathic pain in patients with myelopathy associated with HTLV-1. Braz J Infect Dis 2008;12(Suppl 1):S14

14. Tavares IR, Franzoi AC, Araújo AQC. Low-back pain in HTLV-Iassociated myelopathy/tropical spastic paraparesis: nociceptive or neuropathic? Spinal Cord 2010;48:134-137.

15. Boureau F, Doubrère JF, Luu M. Study of verbal description in neuropathic pain. Pain 1990;42:145-152.

16. Miller RG. Role of fatigue in limiting physical activities in humans with neuromuscular diseases. Am J Phys Med Rehabil 2002;81(Suppl):S99S107.

17. Drory VE, Goltsman E, Reznik JG, Mosek A, Korczyn AD. The value of muscle exercise in patients with amyotrophic lateral sclerosis. J Neurol Sci 2001;191:133-137.

18. Diniz MS, Feldner PC, Castro RA, Sartori MG, Girão MJ. Impact of HTLV-I in quality of life and urogynecologic parameters of women with urinary incontinence. Eur J Obstet Gynecol Reprod Biol 2009;147:230233.

19. Tate DG, Kalpakjian CZ, Forchheimer MB. Quality of life issues in individuals with spinal cord injury. Arch Phys Med Rehabil 2002;83(Suppl 2):S18-S25.

20. $\mathrm{KuJH}$. Health-related quality of life in patient with spinal cord injury: review of the short form 36 Health Questionnaire Survey. Yonsei Med J 2007; $48: 360-370$ 